Research Article

\title{
Nanocomposite Ag@AgCl/ZnO for efficient hydrogen generation through water splitting
}

\author{
Niranjan Kumar Mandawat ${ }^{1} \cdot$ Hari Shanker Sharma ${ }^{2} \cdot$ Neelu Chouhan $^{1}$
}

(c) Springer Nature Switzerland AG 2019

\begin{abstract}
We had successfully prepared the microwave assisted lotus shaped Ag@AgCl/ZnO nanocomposite (NC) of size $57.72 \mathrm{~nm}$, in aqueous media at $90^{\circ} \mathrm{C}$ for $7 \mathrm{~min}$ heating. The conventional single pot refluxing method was also used to prepare NCs with spherical shaped nanoparticles of size $59.12 \mathrm{~nm}$ at $90^{\circ} \mathrm{C}$ heating for $3 \mathrm{~h}$. X-ray diffraction data of the $\mathrm{Ag@AgCl} / \mathrm{ZnO}$ NCs synthesized by the both methods, confirmed that the nanocomposite crystallized in three phases i.e. face-centered cubic $(\mathrm{AgCl})$, cubic (nanosilver) and wurtzite hexagonal phase $(\mathrm{ZnO})$. Energy dispersive $\mathrm{X}$-rays corresponding to the electron microscopy analysis with their elemental mapping, envisioned the surface morphology and elemental composition i.e., $19 \% \mathrm{ZnO}, 13.79 \% \mathrm{AgCl}, 8.08 \% \mathrm{Zn}$ and $26.19 \% \mathrm{Ag}$ in the $\mathrm{NC}$. The $\mathrm{Ag} @ \mathrm{AgCl} / \mathrm{ZnO} \mathrm{NCs}$ exhibited the visible light harvesting ability with band gap i.e. 3.02 and $2.96 \mathrm{eV}$ with SURS selfsensitization of $\mathrm{AgCl}$. Conventionally made sample and microwave assisted sample emits green and yellow-photoluminescence emissions, respectively. FTIR spectra at different stages of the formation of the nanocomposites, visualized the gradual changes in bonding positions of NCs. We utilized this molecular system as an efficient visible-light harvesting optical devices for water splitting. Conventionally and microwave assisted Ag@AgCl/ZnO samples, librated 6082.9 and $6782.32 \mu \mathrm{mol} \mathrm{H}_{2} \mathrm{~h}^{-1} \mathrm{~g}^{-1}$, optimum hydrogen in $8 \mathrm{~h}$, respectively, through photocatalytic water splitting under AM $1.5 \mathrm{G}$ irradiation.
\end{abstract}

\section{Graphical abstract}
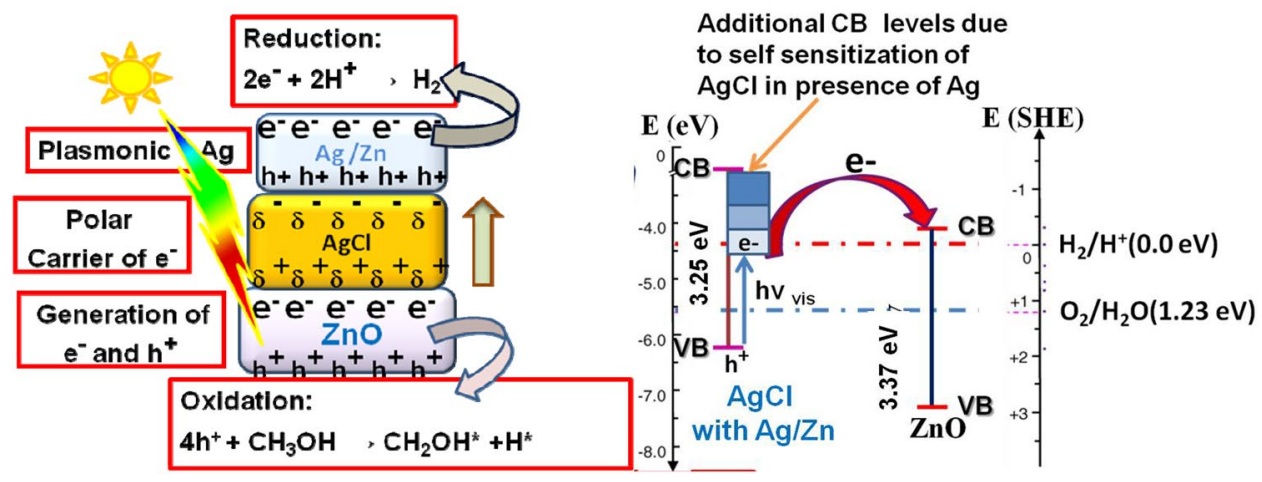

Electronic supplementary material The online version of this article (https://doi.org/10.1007/s42452-019-0578-1) contains supplementary material, which is available to authorized users.

Neelu Chouhan, niloochauhan@hotmail.com | 'Department of Pure and Applied Chemistry, University of Kota, MBS Road Near Kabir Circle, Kota, Rajasthan 324005, India. ${ }^{2}$ Department of Chemistry, Government College, Kota, Rajasthan 324005, India. 
Keywords Nanocomposite·Ag@AgCl/ZnO - One-pot synthesis · Microwave-assisted synthesis · Plasmonic silver nanoparticles $\cdot$ Water splitting $\cdot$ Hydrogen generation

\section{Introduction}

World had eventually witnessed the ecosystem degradation and political hostility on energy lines, which is a matter of prime global concern. Therefore, we all are looking forward to the clean energy sources that can be replaced with the present conventional energy sources (as a fuel or energy carrier) and save environment. Hydrogen rated as the best option on its fuel merits i.e. high energy density $(142 \mathrm{~kJ} / \mathrm{kg})$, high heating value $(52,000 \mathrm{Btu} / \mathrm{lb})$, high auto ignition temperature $\left(585^{\circ} \mathrm{C}\right)$, high fuel efficiency $(75 \%)$ and widest range of flammability (4-75\%), etc. In contrast to the current hydrogen generation practices (steam reforming of methane), the use of solar energy and carbon-less fuel i.e. water along with a suitable photocatalyst, is an eco-benign way of hydrogen production. A wide variety of photocatalytic materials (oxides, sulfides, nitrides, nanocomposites, etc.) are tested for hydrogen generation via water spitting. Unfortunately, most of them failed on the criteria of stability (in water and light), cost and efficiency (>10\%), simultaneously. Out of these classes nanocomposite is the least studied class. Therefore, we had choosen to work on nanocomposites. Few of the prominently studied nanocomposite systems are: modified graphenes [1-5], CdS/Au/g- $\mathrm{C}_{3} \mathrm{~N}_{4}$ [6], CuS/ $\mathrm{TiO}_{2}$ [7], $\mathrm{NiO}_{x}$ (Ni/NiO)@ calcium tantalite [8], Ag/AgCl@ $\mathrm{ZnO}$ [9-13], etc. Recently, silver halides based plasmonic nanoparticles (NPs) have been attracted the attention as a superb class of nanocomposites (NCs) that used for visiblelight-harvesting device [9-13]. Although, due to instability under sunlight [14], silver halides AgX were seldom used as photocatalysts. However, Kakuta et al. [15] studied the $\mathrm{Ag}^{0}$ supported $\mathrm{AgBr}$ dispersed on a silica that used for continuous $\mathrm{H}_{2}$ production (1.00 mmol h $\mathrm{m}^{-1} \mathrm{~g}^{-1}$ after $2 \mathrm{~h}$ ) in $20 \%$ aqueous $\mathrm{CH}_{3} \mathrm{OH}$ (as hole scavenger). They had observed that Ag NPs deposited on $\mathrm{AgBr}$, supported by silica are not destroyed under successive UV/Vis illumination till $200 \mathrm{~h}$, thus assembly $\mathrm{Ag} / \mathrm{AgBr}$ on silica, was able to act as a stable photocatalyst under visible light, and inspired to synthesized the first visible-light plasmonic photocatalyst Ag@AgCl. Moreover, Schürch et al. [16] proved that the $\mathrm{AgCl}$ deposited on a conducting support (Au coated FTO) was used to photocatalyse the water for $\mathrm{O}_{2}$ production $\left(160 \mathrm{nmol} \mathrm{h}^{-1}\right)$ in the presence of silver ions (as electron scavenger), under UV/Vis light exposure. Similarly, 3D-hierarchical superstructures, concave cubes, and cubes of $\mathrm{AgCl}$, were used as photocatalyst for $\mathrm{O}_{2}$ generation via water splitting with their activity are $254 \mathrm{mmol} \mathrm{g}^{-1}$ for hierarchical superstructures, $187 \mathrm{mmol} \mathrm{g}^{-1}$ of concave cubic $\mathrm{AgCl}$ and $136 \mathrm{mmol} \mathrm{g}^{-1}$ of cubic $\mathrm{AgCl}$ in $5 \mathrm{~h}$ [17]. The photoactivity of $\mathrm{AgCl}$ in presence of $\mathrm{Ag}^{+}$ions, extended from the UV to the visible light region under the process known as self-sensitization, $[18,19]$ which is due to the formation of silver species during the photoreaction, as follows (Eqs. 1-7):

$$
\begin{aligned}
& {\left[n \mathrm{Ag}^{+}, m \mathrm{maCl}\right]+\frac{r}{2} \mathrm{H}_{2} \mathrm{O} \longrightarrow \operatorname{light}\left[(n-r) \mathrm{Ag}^{+}, m \mathrm{AgCl}, r g^{0}\right]} \\
& \quad+r \mathrm{H}^{+}+\frac{r}{4} \mathrm{O}_{2}
\end{aligned}
$$

light $\left[(n-r) \mathrm{Ag}^{+}, m A g C l, r g^{0}\right] \longrightarrow \operatorname{light}\left[n \mathrm{Ag}^{+}, m A g C l\right]+r e^{-}$

$[m A g C l]\left\{\mathrm{Ag}^{+}\right\}_{s} \longrightarrow \operatorname{light}[(m-1) \mathrm{AgCl}]\left\{\mathrm{Ag}^{+} \mathrm{Ag}^{0}\right\}_{s, i}+\left[\mathrm{Cl}{ }_{s}\right]$

$2 \mathrm{Cl}_{\mathrm{s}} \rightarrow \mathrm{Cl}_{2}$

$\mathrm{Cl}_{2}+\mathrm{H}_{2} \mathrm{O} \rightarrow \mathrm{HOCl}+\mathrm{H}^{+}+\mathrm{Cl}^{-}$

$2 \mathrm{HOCl}+\mathrm{Ag}^{+}$(catalyst) $\rightarrow \mathrm{O}_{2}+2 \mathrm{H}^{+}+2 \mathrm{Cl}^{-}$

$(m-1) \mathrm{AgCl}+\mathrm{Ag}^{+}+\mathrm{Cl}^{-} \rightarrow[\mathrm{mAgCl}]$

Equations (1) to (7), had been experimentally and theoretically analyzed $[18,19]$. The comparison of experimental and calculated values for the ionization energy for different sized Ag clusters shows that Ag levels are located below the conduction band edge of $\mathrm{AgCl}$. Additional $\mathrm{AgCl}$ surface states (SURS), as well as metal induced gap states (MIGS) from $\mathrm{Ag} / \mathrm{AgCl}$ cluster composites are also present in the band gap region of silver chloride that induced the self-sensitization in $\mathrm{AgCl}$ [20-23]. Therefore, $\mathrm{Ag} / \mathrm{AgX}$ on variety of support can be used as good photocatalytic system (Table 1).

Some of the notable nanocomposite plasmonic materials are $\mathrm{Ag@AgBr}$ [24], $\mathrm{Au} / \mathrm{TiO}_{2}$ [25], gold/layered double hydroxides [26], Ag/AgCl/ZnO [27], Ag embedded $\mathrm{TiO}_{2}$ [28], Au/ZnO NRs [29], graphene oxide (GO) enwrapped $\mathrm{Ag} / \mathrm{AgX}(\mathrm{X}=\mathrm{Cl}, \mathrm{Br}$ ) [30], Ag/AgBr@TiO 2 [31], Ag/AgCl@ $\mathrm{H}_{2} \mathrm{WO}_{4} \cdot 3 \mathrm{H}_{2} \mathrm{O}$ [32], $\mathrm{AgBr} / \mathrm{WO}_{3}$ [33], and $\mathrm{Ag} / \mathrm{ZnO}$ nanorods (NRs) [34], which can act as a good plasmonic nanocomposites, as shown in Table 1. Most of the above molecular devices had been used to degraded dye/organic pollutants (methylene blue, methyl orange, VOCs, ethanol/methanol) and only few of the composite plasmonics, were used to produce hydrogen such as gold/layered double hydroxides $\left(127 \mu \mathrm{mol} \mathrm{h}^{-1}\right.$ for Au/ZnAlCeLDH and $94 \mu \mathrm{mol} \mathrm{h}^{-1}$ of 
Table 1 Some state-of-art plasmonic catalyst supported systems for hydrogen generation

\begin{tabular}{|c|c|c|c|c|c|c|c|}
\hline SI. no. & $\begin{array}{l}\text { Plasmonic material } \\
\text { supported photo- } \\
\text { catalyst }\end{array}$ & Light source & $\begin{array}{l}\text { Conditions for } \mathrm{H}_{2} \\
\text { generation }\end{array}$ & $\begin{array}{l}\text { Amount of } \mathrm{H}_{2} \\
\text { generation } \\
\mu \mathrm{mol} \mathrm{H}_{2} \mathrm{~h}^{-1} \mathrm{~g}^{-1}\end{array}$ & $\begin{array}{l}\text { Amount of } \mathrm{O}_{2} \\
\text { generation } \\
\mu \mathrm{mol} \mathrm{O}_{2} \mathrm{~h}^{-1} \mathrm{~g}^{-1}\end{array}$ & Year & $\begin{array}{l}\text { Research group } \\
\text { [Reference No.] }\end{array}$ \\
\hline 1 & $\begin{array}{l}\mathrm{Ag}^{0} \text { supported-AgBr } \\
\text { dispersed on silica- } \\
\text { dioxide support }\end{array}$ & $\begin{array}{l}100 \text { W high-pressure } \\
\text { Hg lamp-with IR } \\
\text { filter }\end{array}$ & $\begin{array}{l}20 \% \mathrm{CH}_{3} \mathrm{OH} \text { (hole } \\
\text { scavenger) in } \mathrm{H}_{2} \mathrm{O}\end{array}$ & 1000 after $2 \mathrm{~h}$ & - & 1999 & Kakuta et al. [15] \\
\hline 2 & $\begin{array}{c}\mathrm{Ag} @ \mathrm{AgCl} \text { deposited } \\
\text { on Au coated FTO }\end{array}$ & UV-Vis light exposure & $\begin{array}{l}\text { In presence of } \mathrm{Ag}^{+} \\
\text {ions }\end{array}$ & - & $0.160 \mathrm{~mol} \mathrm{~h}^{-1}$ & 2002 & SchKrch et al. [16] \\
\hline 3. & $\begin{array}{l}\text { 3D hierarchical super- } \\
\text { structures, concave } \\
\text { cubes, and cubes of } \\
\mathrm{AgCl}\end{array}$ & 300 W Xe arc lamp & $\begin{array}{l}\text { In presence of } \mathrm{Ag}^{+} \\
\text {ions }\end{array}$ & - & $\begin{array}{l}254,000 \\
187,000 \text { and } \\
136,000 \text { in } 5 \mathrm{~h}\end{array}$ & 2012 & Lou et al. [17] \\
\hline 4. & $\begin{array}{c}\mathrm{Au} / \mathrm{ZnAlCeLDH} \text { and } \\
\mathrm{Au} / \mathrm{ZnAILDH}\end{array}$ & Solar light exposure & $20 \%$ methanol & 127 and 94 & - & 2013 & Carja et al. [26] \\
\hline 5. & $\begin{array}{l}\text { Ag/ZnONRs and } \\
\text { ZnONRs }\end{array}$ & Xe light source & $20 \%$ methanol & 8.7 and 4.3 & - & 2013 & Chen et al. [34] \\
\hline 6 & $\mathrm{Ag} / \mathrm{AgCl} / \mathrm{ZnO}$ & Xe light source & $20 \%$ methanol & $\begin{array}{l}6082.9 \text { (one pot) } \\
\text { and } 6782.32 \\
\text { (microwave) }\end{array}$ & - & 2019 & Present work \\
\hline
\end{tabular}
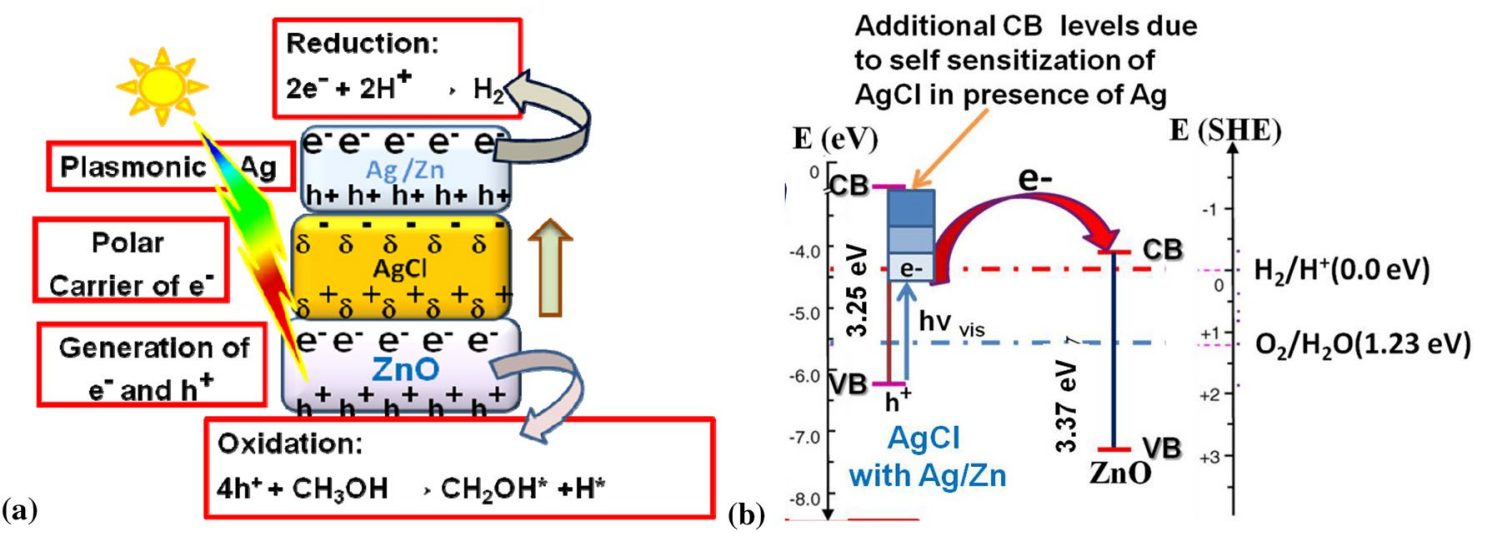

Scheme 1 a Schematic representation of the overall water splitting phenomenon using Ag NPs embedded AgCl-ZnO NCs and $\mathbf{b}$ comparative energy level diagram of nanocomposite device $\mathrm{Ag} @ \mathrm{AgCl} / \mathrm{ZnO}$ with their respective band positions [20-22]

$\mathrm{H}_{2}$ for Au/ZnAlLDH) [26], Ag/ZnONRs (8.7 $\mu \mathrm{mol} \mathrm{h}^{-1}$ of $\mathrm{H}_{2}$ by $\mathrm{Ag} / \mathrm{ZnO}$ and $4.3 \mu \mathrm{mol} \mathrm{h}^{-1}$ of $\mathrm{H}_{2}$ by $\mathrm{ZnO}$ ) [34]. In this direction, several advance synthesis methods such as: ultrasonic assisted deposition-precipitation method [35], ployol process $[36,37]$, reconstruction process [38], single pot refluxing [27], ionic liquids-assisted hydrothermal method [39], etc., had been used to prepare NCs. Microwave (MW) assisted synthesis is one of the eco-friendly method for molecular assemblies fabrication, where MW-heating provided faster and uniform heating profile than the conventional thermal heating. Therefore, MW assisted-synthesis leads not only homogenous nucleation but also accelerate the reaction rate, improve yield, shorten the reaction time, produce small sized particle of high purity with narrow particle size distribution, and improve physicochemical properties [40]. Some notable materials such as $\mathrm{SnO}_{2}$ [41], ZnO [42], Ag [43], Pt [44], CuS [45], etc., were fabricated using MW assisted synthesis. But the record was not found for MW assisted synthesis of the Ag@AgCl/ZnO NC. Therefore, we employed the MW assisted synthesis first time for NCs preparation that consist of plasmonic silver $\mathrm{NPs}$ embedded in $\mathrm{ZnO}$ and $\mathrm{AgCl}$ matrix, which was used for water splitting to generate hydrogen. Conventional one pot refluxing method was also used to synthesize the Ag@AgCl/ZnO NC [27] in aqueous medium. Under the sunlight exposure, $\mathrm{ZnO}$ and $\mathrm{AgCl}$ generates photoelectrons and -holes and $\mathrm{AgCl}$ (with expanded CB energy levels) plays an important role of polar carrier for electrontransport from plasmonic material (Ag NPs) to $\mathrm{ZnO}$ and whole assembly become capable to harvest visible light, 
as it schematically illustrated by the Scheme 1a and Energy diagram 1b. Therefore, we can say the nanocomposite Ag@ $\mathrm{ZnO} / \mathrm{AgCl}$, has the better compatibility for visible light harvesting and supression in the recombination rate of photo carriers. That will be ultimately enhanced the hydrogen generation efficiency of the device. In addition to above, to understand the nature of nanocomposite the advanced technical approaches were used to address the characterization of the device.

\section{Experimental design, materials, and methods}

\subsection{Materials}

All chemicals were used as-purchased (of make Sigma Aldrich) in synthesis and water splitting application without further purification. These chemicals are: hexahydrated-zinc nitrate, sodium chloride, sodium hydroxide, and silver nitrate, terepthalic acid, etc.

\subsection{Synthesis}

\subsubsection{Conventional method}

Ag nanoparticles-supported $\mathrm{ZnO} / \mathrm{AgCl} \mathrm{NCs}$ were fabricated by using one-pot refluxing method as described somewhere else [27]. In which, $5.22 \mathrm{~g}$ hexahydrated zinc nitrate and $2.11 \mathrm{~g}$ silver nitrate were mixed in $50 \mathrm{~mL}$ of deionised water (DIW) and stirred at room temperature and followed by the addition of aqueous $\mathrm{NaOH}(5 \mathrm{M})$ to adjust the $\mathrm{pH}$ of the solution 10 . Here, $\mathrm{NaOH}$ with $\mathrm{pH} 10$ is act as a reducing agent because the hydroxyl ions of $\mathrm{NaOH}$ are capable of donating electrons to $\mathrm{AgNO}_{3}$ and $\mathrm{ZnNO}_{3} \cdot 6 \mathrm{H}_{2} \mathrm{O}$, results in their reduction in $\mathrm{Ag}$ and $\mathrm{Zn}$. During the above reaction, $\mathrm{NaCl}$ act as a dielectric material in production of $\mathrm{AgCl}$ and $\mathrm{ZnO}$. Therefore, above mixture was treated with $1.450 \mathrm{~g} \mathrm{NaCl}$ in $20 \mathrm{~mL}$ of water. Then, the suspension was refluxed at $90^{\circ} \mathrm{C}$ for $3 \mathrm{~h}$. Resulting product was centrifuged and washed several times with DIW and ethanol and dried in an oven at $60^{\circ} \mathrm{C}$ for $24 \mathrm{~h}$.

\subsubsection{Microwave method}

Microwave synthesizer (CEM, model-Discover) was opted to prepare the AgNPs embedded $\mathrm{ZnO} / \mathrm{AgCl} \mathrm{NCs}$ with $0.383 \mathrm{~mol}$ fraction of silver chloride with respect to $\mathrm{ZnO}$. A sundry of $5.220 \mathrm{~g} \mathrm{Zn}\left(\mathrm{NO}_{3}\right)_{2} \cdot 4 \mathrm{H}_{2} \mathrm{O}$ and $2.110 \mathrm{~g}$ $\mathrm{AgNO}_{3}$, were made in $50 \mathrm{~mL}$ of deionised water (DIW) and stirred at room temperature. Thereafter the aqueous $\mathrm{NaOH}$ (5 M) was added in the solution to adjust the
$\mathrm{pH}$ of the solution 10 . Above solution was treated with $1.450 \mathrm{~g} \mathrm{NaCl}$ in $20 \mathrm{~mL}$ of water. Then, the suspension was heated in microwave at $90^{\circ} \mathrm{C}$ for $7 \mathrm{~min}$. Resulted product was centrifuged and washed several times with DIW and ethanol and dried in an oven at $60^{\circ} \mathrm{C}$ for $24 \mathrm{~h}$.

\subsection{Characterization}

Several techniques were used to characterize the nanocomposite Ag@AgCl/ZnO using technical tools such as: UV-Vis absorption spectroscopy, FE-SEM, energy dispersive $\mathrm{X}$-rays (EDX), spectroflurometery, X-ray diffraction (XRD), and FT-IR, etc. The crystalline nature of nanocomposite was characterized by $\mathrm{XRD}$, using diffractometer (PANalytical; Model: Xpert-Pro) of MNIT, Jaipur, well equipped with $\mathrm{Ni}-\mathrm{K}_{\beta}$ filter for $\mathrm{CuK}_{\alpha 1}$ radiation at $40 \mathrm{kV}$ voltage and $30 \mathrm{~mA}$ current. Morphology of the sample was evaluated by using FESEM (JEOL; Model: JSM-6700F). The UV-Vis spectra were recorded with multimode microplate reader (Lab India; Model: $3000^{+}$with Diffuse Reflectance Spectroscopy) in the wavelength range between 200 and $800 \mathrm{~nm}$. An FT-IR spectrum was recorded using spectrophotometer (Bruker; Model:Tensor 27) available in our institute. Furthermore, photoluminescence emission (PLE) spectrum of the $\mathrm{Ag} @ \mathrm{AgCl} /$ $\mathrm{ZnO}$ nanocomposite material was recorded by using spectrofluorimeter (Simandzu; Model: RF-5301) of our department.

\subsection{Analysis of hydroxyl radical (.OH) in photocatalytic solution}

The hydroxyl radicals $\left({ }^{*} \mathrm{OH}\right)$ formed during the photo-illumination of the samples/water interface, can be traced by the use of basic terephthalic acid (as a probe molecule) solution in the photoluminescence (PL) method using double beam spectrofluorimeter [23]. In this method, the hydroxylation of the terephthalic acid was taken place when it reacted with ${ }^{*} \mathrm{OH}$ radical that resulted in the product 2-hydroxyterephtalic acid (HTA) formation at the water/catalyst interface, which was exhibited by the PLE signal around $428 \mathrm{~nm}$ at the excitation wavelength of $315 \mathrm{~nm}$. The intensity of the PLE peak of 2-hydroxyterephtalic acid is directly proportional to the amount of ${ }^{*} \mathrm{OH}$ radicals produced in the water. Under the experimental procedure $0.3 \mathrm{~g}$ of the sample was added to $110 \mathrm{~mL}$ of $5 \times 10^{-4} \mathrm{M}$ terephthalic acid $(\mathrm{pH}=10)$ that was prepared in aqueous $2 \times 10^{-3} \mathrm{M} \mathrm{NaOH}$ [23]. Afterwards the solution was exposed to the $300 \mathrm{~W}$ Xe light source, by keeping the other experimental conditions same as used in measurement of photocatalytic water splitting activity. Spectrofluorimeter 
Fig. 1 Diffraction patterns of the nanocomposite Ag@AgCl/ $\mathrm{ZnO}$, synthesized by one pot and microwave method. a The XRD peaks are exactly matched to those of the bulk FCC chlorargyrite phase (JCPDS Card No. 31-1238) of the $\mathrm{AgCl}$, cubic phase of Ag (JCPDS Card No. 04-0783 of pure silver and FCC zinc blende crystalline phase (JCPDS Card No. 80-0020; ZnS) of $\mathrm{ZnO}$. b Enlarge peaks of $\mathrm{AgCl}(420)$ and $\mathrm{Ag}$ (311) was observed at $76.68^{\circ}$

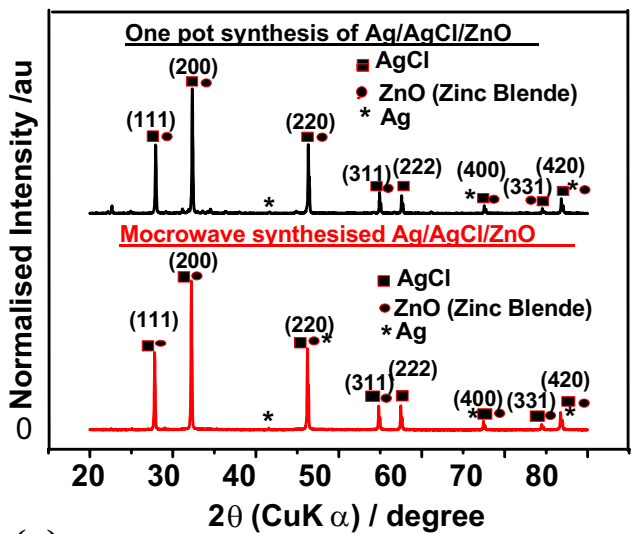

(a)

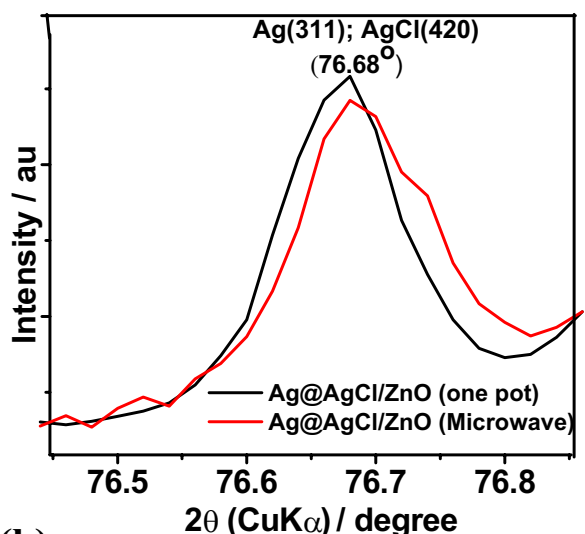

(b)
(Simandzu; Model: RF-5301) of our institute was used to measure the PLE spectrum of the above mentioned solution at room temperature at different time interval.

\subsection{Water splitting analysis}

Photocatalytic $\mathrm{H}_{2}$ evolution power testing of the as synthesised nanocomposite was carried out in a $20 \%$ methanolic (hole-scavenger) solution of $\mathrm{Ag} @ \mathrm{AgCl} / \mathrm{ZnO}$ samples at RT. Where, $0.30 \mathrm{~g}$ of the $\mathrm{Ag} @ \mathrm{AgCl} / \mathrm{ZnO}$ in an aqueous methanolic solution $\left(160 \mathrm{~mL} \mathrm{H}_{2} \mathrm{O}\right.$ and $40 \mathrm{~mL} \mathrm{CH}_{3} \mathrm{OH}$ ) was suspended in a double walled reaction cell of Pyrex glass, equipped with a quartz window. Reaction cell was connected to a closed gas circulation (Argon) of 1 atmosphere pressure to evacuate the solution several times up to the complete removal of the air from the reaction vessel and then system was irradiated by a light source ( $300 \mathrm{~W}$ Xe lamp) for the photocatalytic observations. The amount of $\mathrm{H}_{2}$ evolved during the photocatalytic experiment, was monitored using gas chromatography that was equipped with a thermal conductivity detector (TCD, GC-8A, China gas chromatograph; and Ar as carrier gas).

\section{Result}

The phase purity of the Ag@AgCl/ZnO NC was tested using XRD profile, depicted in Fig. 1a, b. Diffraction patterns of the studied samples are found at $27.942^{\circ}(111)$, $32.34^{\circ}(200), 46.34^{\circ}(220), 54.94^{\circ}(311), 57.58^{\circ}(222)$, $67.54^{\circ}(400), 74.76^{\circ}(331)$ and $76.82^{\circ}(420)$ attributed to the highly crystalline two prominent phases that corresponds to the face-centered cubic (chlorargyrite) phase (reference JCPDS Card No. 31-1238) of the $\mathrm{AgCl}$ with their cell parameters [46]: $a=b=c=5.545 \AA a=\beta=\gamma=90^{\circ}$ at $z=4$, and space group Fm $3 \mathrm{~m}$ (225) and the FCC (zinc blende) crystalline phase (reference JCPDS Card No. 80-0020; ZnS) of $\mathrm{ZnO}[47,48]$ with their cell parameters: $\mathrm{a}=\mathrm{b}=\mathrm{c}=5.345 \AA, \mathrm{a}=\beta=\gamma=90^{\circ}$ at $\mathrm{z}=4$ and space group F4-3m (216). The careful examination of diffraction peaks exhibits tiny peaks at $38.56^{\circ}(111), 46.34^{\circ}(200), 67.54^{\circ}$ (220), $76.82^{\circ}(311)$ position that belongs to the standard JCPDS Card No. 04-0783 of pure silver (cell constants $\mathrm{a}=\mathrm{b}=\mathrm{c}=4.0857 \AA, a=\beta=\gamma=90^{\circ}$ at $\mathrm{z}=4$ and space group Fm3m (225) [46] that also confirmed the presence of the small particles of silver and their size was calculated by using the Scherrer formula. Figure $1 \mathrm{~b}$ represented the blue shift of enlarged peak of $\mathrm{AgCl}(420)$ and $\mathrm{Ag}(311)$ at $76.68^{\circ}$ for the nanocomposite $\mathrm{Ag} @ \mathrm{AgCl} / \mathrm{ZnO}$ synthesized by one pot and microwave methods from their standard positions i.e. $77.50^{\circ}$ and $77.66^{\circ}$, respectively.

The elemental composition of the nanocomposite was confirmed by respective EDX profile and FESEM elemental mapping, which is represented by Fig. 2a, d, e. No characteristic peaks for the elements other than $\mathrm{Zn}\left(27.08 \%\right.$; at $\left.\mathrm{K}_{a}=8.63 \mathrm{keV} ; \mathrm{L}_{a}=1.012 \mathrm{keV}\right) \mathrm{Ag}(39.98 \%$; at $\left.\mathrm{L}_{a}=2.984 \mathrm{keV}\right), \mathrm{Cl}\left(13.79 \%\right.$; at $\left.\mathrm{K}_{a}=2.621 \mathrm{keV}\right)$ and $\mathrm{O}$ $\left(19 \%\right.$ at $\left.K_{a}=0.525 \mathrm{keV}\right)$ were found in the EDX profile of the Ag@AgCl/ZnO, as illustrated by the Fig. 2a. The actual concentration of oxygen can't be determined precisely due to the presence of the oxygen in air. As per XRD analysis nanocomposite crsytalised in three phases i.e. $\mathrm{ZnO}, \mathrm{AgCl}$ and $\mathrm{Ag} / \mathrm{Zn}$. Therefore, EDX suggested that nanocomposite consist of $19.15 \% \mathrm{ZnO}, 13.79 \% \mathrm{AgCl}, \mathrm{Ag}$ (26.19\%) and $\mathrm{Zn}$ (7.39\%). Surface morphology and particle size of the nanocomposite was investigated by the FESEM images (Fig. 2b, C), as nanolotus shaped particle of size 45.08-60.77 $\mathrm{nm}$ (aggregation of particles) for the microwave synthesized sample and 50.87-79.19 nm sized spherical particles for the one plot synthesized sample of the nanocomposite $\mathrm{Ag} @ \mathrm{AgCl} / \mathrm{ZnO}$.

Figure 3 a demonstrated the UV-Vis diffuse reflectance spectra [Kubelka-Munk function $F(R)$ Vs wavelength] with peaks at $300.4 \mathrm{~nm}, 352.0 \mathrm{~nm}$ and a very weak and broad peak found between 407.9 and $700 \mathrm{~nm}$. Splitting in first absorption peak is found due to the presence 

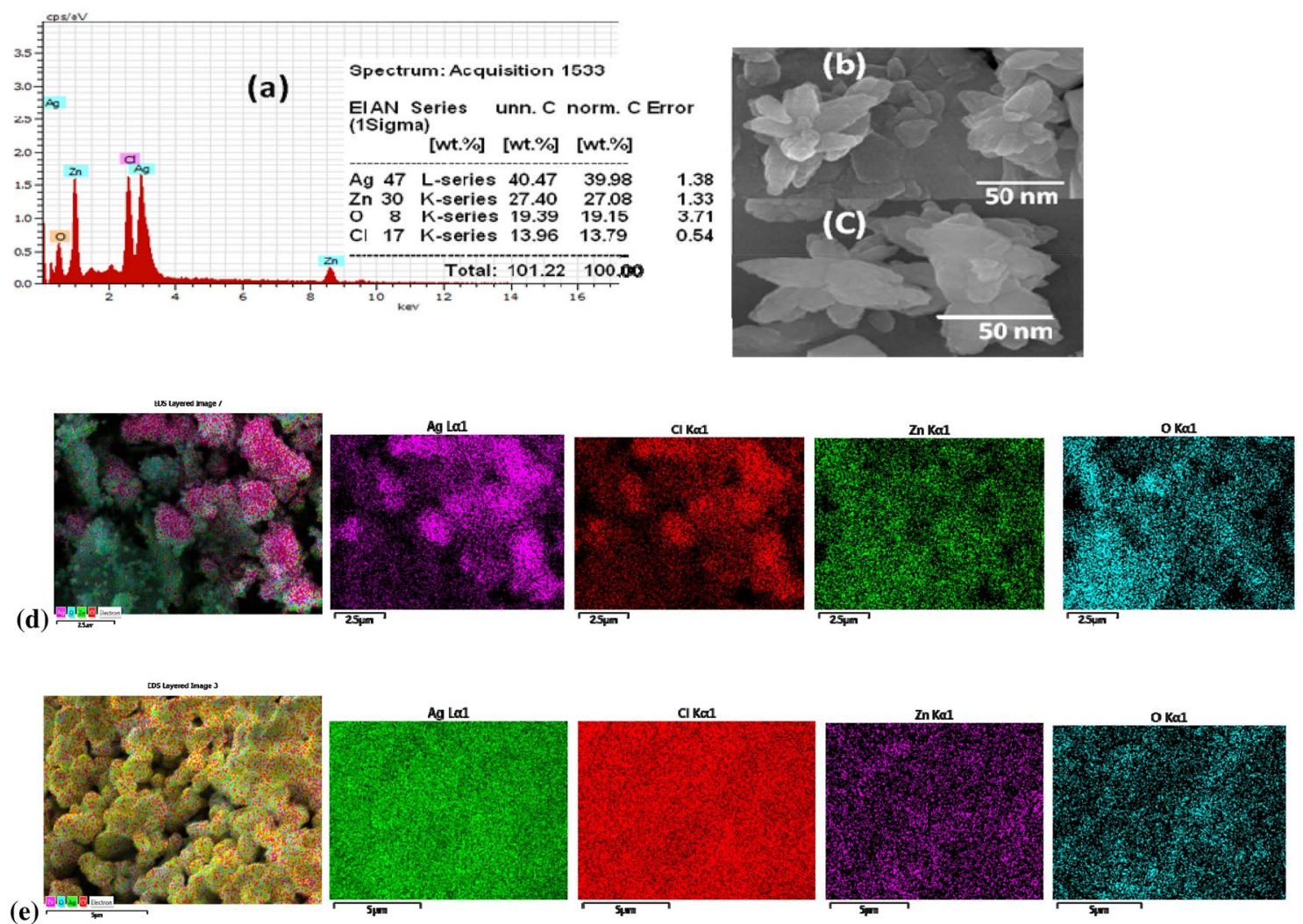

Fig. 2 Nanocomposite $\mathrm{Ag} @ \mathrm{AgCl} / \mathrm{ZnO}$ with their corresponding a FESEM supported EDX showing elemental presence of Ag, Zn, O and $\mathrm{Cl}$. $\mathbf{b}$ and $\mathbf{c}$ are FESEM images of nanocomposite, prepared by

microwave route. FESEM elemental mapping of $\mathrm{Ag}, \mathrm{Cl}, \mathrm{Zn}$ and $\mathrm{O}$ elements in Ag@AgCl/ZnO for corresponding, $\mathbf{d}$ one pot (conventional) and e microwave-assist synthesized nanocomposite

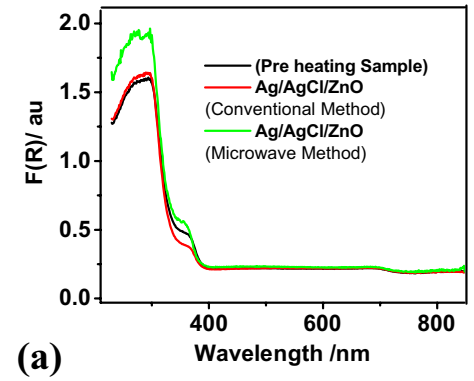

(a)

Fig. 3 a UV-Vis diffuse reflectance spectra of the pre heated sample along with conventional- and microwave-prepared $\mathrm{Ag@AgCl} /$ $\mathrm{ZnO}$ nanocomposites with first excitonic peak around $300.4 \mathrm{~nm}$. b PLE spectra with maxima at $\lambda_{\max }^{\mathrm{em}}=502 \mathrm{~nm}$ under the excitation wavelength $\lambda_{\max }^{\mathrm{ex}}=250 \mathrm{~nm}$ of the sample prepared by one pot

of the two phases i.e. $\mathrm{AgCl}$ and $\mathrm{ZnO}$. These three peaks in UV-Vis absorption spectrum was used to investigate band gap of the nanocomposite $\mathrm{Ag} @ \mathrm{AgCl} / \mathrm{ZnO}$ at $300.40 \mathrm{~nm}\left(E_{\mathrm{g}}^{\mathrm{m}}=3.56 \mathrm{eV}\right.$ and $\left.E_{\mathrm{g}}^{\mathrm{c}}=3.62 \mathrm{eV}\right)$, at $352.00 \mathrm{~nm}$ $\left(E_{g}^{c}=3.02 \mathrm{eV}\right.$ and $E_{g}^{m}=2.96 \mathrm{eV}$ due to additional SURS of $\mathrm{AgCl})$ and at $708.86 \mathrm{~nm}\left(\mathrm{E}_{\mathrm{g}}^{\mathrm{m}}=1.35 \mathrm{eV}\right.$ and $\left.\mathrm{E}_{\mathrm{g}}^{\mathrm{c}}=1.35 \mathrm{eV}\right)$. reflux method and c PLE spectra with maxima at $\lambda_{\max }^{\mathrm{em}}=602 \mathrm{~nm}$ under the excitation wavelength $\lambda_{\max }^{\mathrm{ex}}=300 \mathrm{~nm}$, for the sample prepare using microwave method (CIE plot represented in inset that exhibit the yellow emission)

Where, $E_{g}^{m}$ and $E_{g^{\prime}}^{c}$ are band gap for microwave and convention-method, respectively.

Photoluminescence emission (PLE) spectra of Ag@ $\mathrm{AgCl} / \mathrm{ZnO}$ are revealed by Fig. $3 \mathrm{~b}, \mathrm{c}$, which were taken for the samples prepared by one pot reflux- and microwave assisted-methods, respectively. Figure $3 \mathrm{~b}$ exhibited 
Fig. 4 a PLE spectra changes (Soret-band) at $428.0 \mathrm{~nm}$ wavelength with visible-light irradiation time for the Ag@ $\mathrm{AgCl} / \mathrm{ZnO}$ (microwave) nanocomposite powder dispersed in alkaline terphallic acid solution and $\mathbf{b}$ Q-bands of PLE spectrum at $562.8 \mathrm{~nm}$ and $6320.9 \mathrm{~nm}$ wavelength

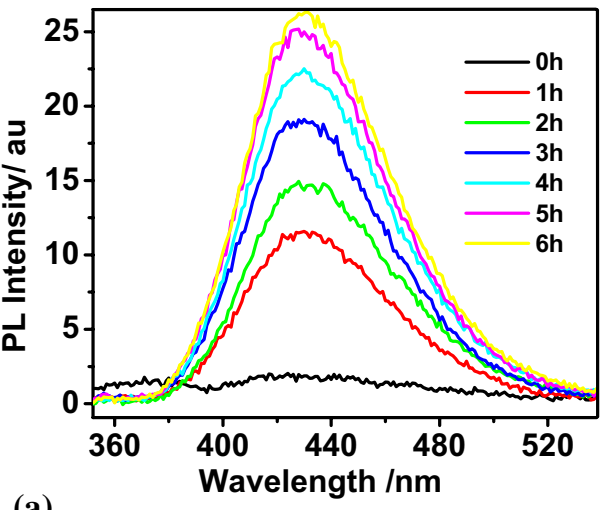

(a)

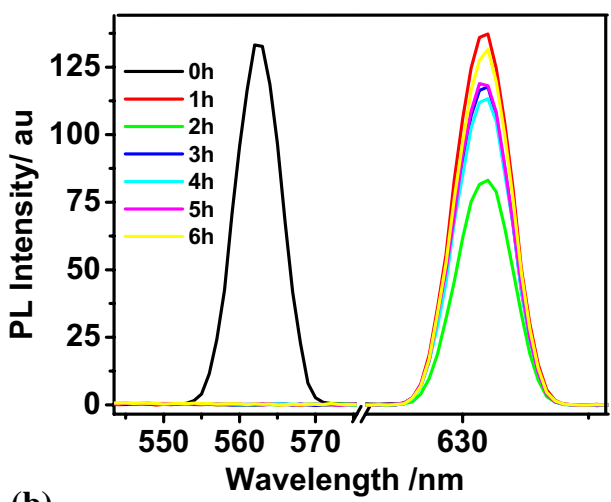

(b)

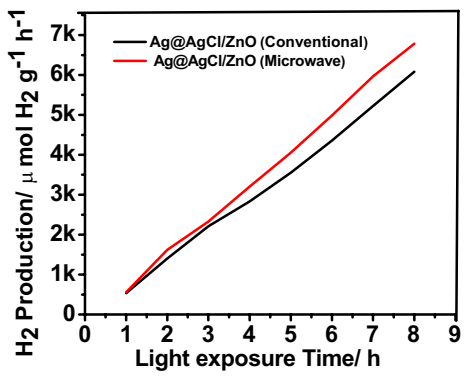

(a)

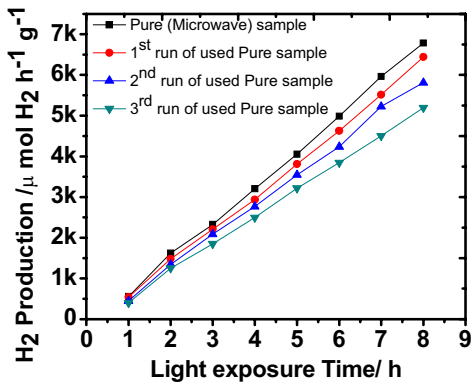

(b)

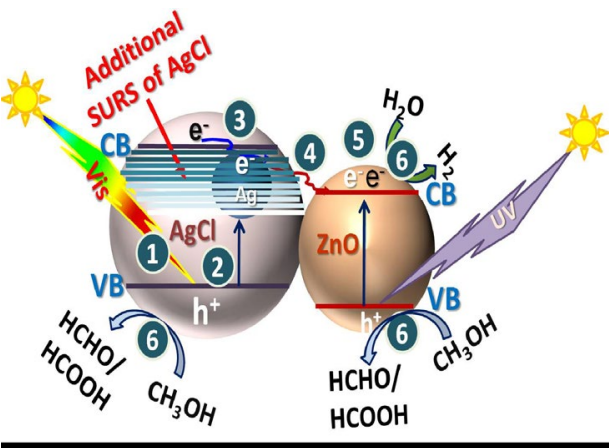

(c)

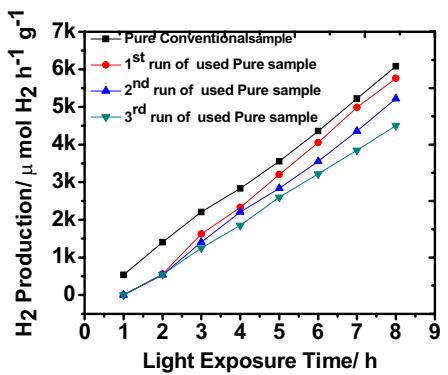

(d)
Fig. 5 Photocatalytic hydrogen by a pristine $N C$ the conventionally (red)- and microwave (green)-method, $\mathbf{b}$ reproducibility check for the synthesized samples, c reprotime-, second time- and third time-used conventionally synthesized sample, with respect to the time ( 1 to $8 \mathrm{~h}$ ) under $300 \mathrm{~W}$ Xe light exposure. $\mathbf{d}$ The electron transfer mechanism for water splitting of nanocomposites the excitation peak at the wavelength of $250 \mathrm{~nm}$ under the exposure of emission light of the wavelength $\lambda_{\max }^{e m}=502 \mathrm{~nm}$ and green light emission spectra was found at $502 \mathrm{~nm}$ under the excitation energy of wavelength $\lambda_{\max }^{e x}=250 \mathrm{~nm}$ for one pot refluxed sample. Similarly, the strong PLE peak was observed for microwave assisted sample at $602 \mathrm{~nm}$ under the excitation energy of wavelength $300 \mathrm{~nm}$, as shown by the Fig. 3c.

Figure 4a illustrated the PLE spectra of the conventionally prepared sample to check the presence of ${ }^{*} \mathrm{OH}$ radical as a PLE signal of Soret-band at $428 \mathrm{~nm}$ and Q-bands at $562.8 \mathrm{~nm}$ and $632.9 \mathrm{~nm}$ at the $315 \mathrm{~nm}$ excitation energy, under visible light irradiation [23].The PLE signal at $428 \mathrm{~nm}$ are the result of the reaction between ${ }^{*} \mathrm{OH}$ radical and terephthalic acid that produces HTA at the water/catalyst interface. The concentration of HTA increases with reaction time ( $0 \mathrm{~h}, 1 \mathrm{~h}, 2 \mathrm{~h}, 3 \mathrm{~h}, 4 \mathrm{~h}, 5 \mathrm{~h}$ and $6 \mathrm{~h}$ ) that reflected the increase in production of ${ }^{*} \mathrm{OH}$ radicals during the reaction (Fig. 4a).

Molecular devices of Ag@AgCl/ZnO NC (prepared via one pot conventional and microwave method), produced hydrogen in $20 \%$ methanolic DIW, under visible light exposure of $300 \mathrm{~W}$ Xe light. Amount of the released hydrogen, was significantly enhanced with increasing exposure time (i.e. 1, 2, 3, 4, 5, 6, 7 and $8 \mathrm{~h}$ ) viz. 536.71 and 556.8, 1404.41 and $1621.21,2207.86$ and $2325.37,2835.26$ and 3203.09 , 3554.11 and $4053.44,4359.24$ and $4987.66,5221.07$ and $5761.86,6082.9$ and $6782.32 \mu \mathrm{mol} \mathrm{H}_{2} \mathrm{~h}^{-1} \mathrm{~g}^{-1}$, corresponding to the conventional and microwave prepared nanocomposite samples under $300 \mathrm{~W}$ Xe light irradiation 
(Fig. 5a-c) at room temperature. Above used samples further used for three time to check the reproducibility of the samples, that was found good for all studied samples with low decrease in photocatalytic activity (Fig. 5b, c).

\section{Discussion}

The XRD study confirms that the nanocomposite Ag@ $\mathrm{AgCl} / \mathrm{ZnO}$ crystallized in their three major phases i.e. $\mathrm{AgCl}, \mathrm{Ag}$ and $\mathrm{ZnO}$. The particle size of these nanocomposites, prepared by one pot conventional and microwave synthesis was determined using Scherrer formula viz. $57.72 \mathrm{~nm}$, and $59.12 \mathrm{~nm}$, respectively with their corresponding lattice strain 0.0022 and 0.0023 . Lattice strain associated with the dislocations in crystal structure could either be caused a crystallographic defects or irregularity in lattice arrangement due the presence of three different phases [49]. These topological defects can be highly influenced by the material's native properties. The X-ray diffraction profiles can also be used in determination of the dislocation density $(\delta)$ for the samples using following expression given in Eq. (8) [48]:

$\delta=\frac{15 \beta \operatorname{Cos} \theta}{4 a D}$

where dislocation density $\left[\delta=3.8019 \times 10^{13} \mathrm{~m}^{-2}\right.$ (one pot) and $3.9100 \times 10^{13} \mathrm{~m}^{-2}$ (microwave)] is calculated from broadening of diffraction peak i.e. Full width at its half of maximum intensity $\beta$ (in radian), Bragg's diffraction angle $\theta$ (in degree), lattice constant $a$ (in $\mathrm{nm}$ ) and particle size $D$ (in $\mathrm{nm}$ ). Higher strain and delocalization density of the microwave synthesized sample than conventionally prepared sample is associated with higher number of active sites on the large molecular surface area due to lotus shape of the particle. The presence of $\mathrm{Zn}$ in Ag lattice is also confirmed from blue shift that observed for Ag XRD peaks due to addition of low weighted element $Z n$, as shown in Fig. 1 b.

EDX profile corresponds to the Fig. 2a used to confirm the presence of $20.65 / 19.00 \% \mathrm{ZnO}, 12.98 / 13.79 \% \mathrm{AgCl}$, 4.73/8.08\% $\mathrm{Zn}$ and $28.01 / 26.19 \% \mathrm{Ag}$ in the NCs (one pot reflux-/microwave-method \%). FESEM elemental mapping are shown in Fig. $2 \mathrm{~d}$, e, predicted that the nanoparticles Ag/Zn (nanoparticles of size $30-40 \mathrm{~nm}$ )-loaded $\mathrm{AgCl}$ were well dispersed on $\mathrm{ZnO}$ surface. Above results also revealed that in compare to the six petal-lotus like artifacts of the microwaved sample, the conventionally prepared samples had more homogeneously dispersed elements as illustrated by the Fig. $2 \mathrm{~d}$, e.

Intense UV-Vis absorption peak around $300.40 \mathrm{~nm}$ (Fig. 3a) appeared due to the ligand metal charge transfer (LMCT) $\pi \rightarrow \sigma^{*}$ electron transition (the charge transfer of excitons from the VB to $\mathrm{CB}$ ) in the host material. The broad and small peak at $352.00 \mathrm{~nm}$ comes into view due to the $d-d$ transition of Ag NPs, which were deposited on $\mathrm{AgCl} / \mathrm{ZnO}$ surface [50]. Vigilant inspection of the spectra speculated a broad and weak plateau between 407.9 and $700 \mathrm{~nm}$, also attributed to the $d-d$ orbital interactions of $\mathrm{Ag} / \mathrm{Zn}$ nanoparticles. The ability of visible light absorption for final nanocomposites was drastically enhanced due to the surface plasmonic resonance (SPR) effect of $\mathrm{Ag} / \mathrm{Zn} \mathrm{NPs}$ that associated with the $\mathrm{AgCl}$ surface. This combination (Ag@AgCl) prompts the self-sensitization of $\mathrm{AgCl}$ that result in additional CB levels [21]. Ag levels are located just below the conduction band edge of $\mathrm{AgCl}$, can develop additional $\mathrm{AgCl}$ surface states (SURS), as well as metal induced gap states (MIGS) from Ag@ AgCl composites that present in the band gap region of silver chloride and their presence induce the self-sensitization phenomenon in $\mathrm{AgCl}$ (Scheme 1b) [20].

The Fermi levels of $\mathrm{ZnO} / \mathrm{AgCl}$ and $\mathrm{Ag} \mathrm{NPs}$ are the same in absence of the visible light exposure. But under the visible light irradiation, $\mathrm{ZnO}$ and $\mathrm{AgCl}$ cannot be excited in nanocomposite $\mathrm{Ag} @ \mathrm{AgCl} / \mathrm{ZnO}$ due to its wide band gap therefore their Fermi level remains unchanged. In contrast, plasmonic Ag NPs absorbs visible light because of its SPR absorption, results in the up shift of Fermi level of Ag NPs and produces additional SURS at band gap of $\mathrm{AgCl}$ that facilitate the photoexcited electrons of the $\mathrm{AgCl}$ to be easily injected into the conduction band of $\mathrm{ZnO}$ [51]. These injected electrons can reacted with the adsorbed $\mathrm{O}_{2}$ on surface to produce the superoxide radical anions $\left(\mathrm{O}^{-2 *}\right)$ [52], which is converted into $\mathrm{HOO}^{*}$ radicals and finally, result in $\mathrm{H}_{2} \mathrm{O}_{2}$ on protonation. In alkaline medium under light irradiation, $\mathrm{H}_{2} \mathrm{O}_{2}$ converted into ${ }^{*} \mathrm{OH}$ radicals, which can participation in the water splitting. Excitation and emission (PLE) spectra of sample produced by one pot reflux- and microwave methods, corresponded to the Fig. 3b, c, respectively. Inset of Fig. 3c, exhibit the Commission Internationale de l'Eclairage (CIE) plot of the Ag@ $\mathrm{AgCl} / \mathrm{ZnO}$ (microwave) that confirms the material emits yellow light. The change in preparation method result in shifting of PLE peak from 502 to $602 \mathrm{~nm}$, attributed to the high concentration of the delocalized defects in microwave-prepared sample $\left(\delta=3.9100 \times 10^{13} \mathrm{~m}^{-2}\right)$ than the conventionally (one pot)-prepared sample $\left(\delta=3.8019 \times 10^{13} \mathrm{~m}^{-2}\right)$. Moreover, the photoluminescence phenomena associated with the degree of deviation from the two competing effects i.e. lattice and local coordination effects. The large deviation found for the microwave synthesized sample. Therefore, microwave synthesized samples are more prone to possess more delocalized defects. Green emission (Fig. 3b) of conventionally prepared samples are associated with oxygen deficiency due to a transition between neutral and singly ionized oxygen vacancy [53]. Microwave assisted samples exhibits strong 
and broad yellow defect emission peak (Fig. 3c) due to the surface defects [54], and contributed the yellow emission.

The concentration of ${ }^{*} \mathrm{OH}$ radicals on the surface of the catalyst measured under visible-light exposure in alkaline terephthalic acid solution (initial $\mathrm{pH}=10.5$ ) by photoluminescence method $[23,55,56]$. In basic terephalate solution, the Q-bands further split into two bands owing to vibrational excitations due to transition from ground state to two vibrational states of the excited state $[Q(0,0)$ and $\mathrm{Q}(1,0)][32]$. These transitions can be visualized in the form of Soret band and Q-bands in fluorescence spectra, which was the result of the chemical reactions between basic terephthalic acid and ${ }^{*} \mathrm{OH}$ formed during photocatalytic reactions [57]. Figure 4a exhibited the gradual increase in PLE intensity at $428 \mathrm{~nm}$ wavelength with increasing irradiation exposure time, associated with the Soret-band $\left(\mathrm{S}_{0}\right.$ to $S_{2}$ transition) due conversion of terephthalic acid into HTA (Eq. 9). The molar absorption coefficient for the Soretband is $155-500 \mathrm{M}^{-1} \mathrm{~cm}^{-1}$ [55].

Other PLE peaks found at $562.8 \mathrm{~nm}$ and $632.9 \mathrm{~nm}$, belongs to the Q-bands ( $S_{0}$ to $S_{1}$ transition) $[55,56]$. Furthermore, experiments show that no PL signals for the $\mathrm{Ag} @ \mathrm{AgCl} / \mathrm{ZnO} \mathrm{NC}$ impregnated basic terephthallic acid solution in dark ( 0 h-PLE curve of Fig. $4 a$ ) that result in no production of $-\mathrm{OH}^{*}$ radicals because pure molecular device is activated by visible light (as discussed above). The production of $-\mathrm{OH}^{*}$ radical not only indicated by the decreases in $\mathrm{pH}$ of solution from 10.5 to 8.14 with reaction time but also from the raise in a absorption maximum for PLE peak at $428 \mathrm{~nm}$ (Soret-band) with increasing time.

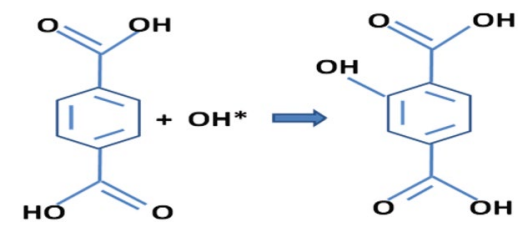

Terephthalic acid + hydroxyl radical $\rightarrow 2$ - hydroxy

Terephthalic acid

The pure water has inefficient energy to decompose all alone but presence of photocatalyst promote this decomposition. Therefore, the study focused on hydrogen production by photocatalytic water splitting using semiconductor NC i.e. Ag/Zn@AgCl/ZnO under light exposure. Minimum four electrons required to stimulate the multistep-water reduction and oxidation reactions of overall water splitting process for $\mathrm{H}_{2}$ and $\mathrm{O}_{2}$ production, respectively. The sacrificial molecules ( $20 \%$ methanol in this case) act as an electron donor/hole-acceptor to enhance the efficiency of the $\mathrm{H}_{2}$ production by consuming the holes and suppress the oxygen production.
Various organic compounds such as alcohols, carboxylic acids, and hydrocarbons, etc., can act as an efficient holescavengers (or electron donors) for the photocatalytic $\mathrm{H}_{2}$ generation. Here, we used methanol as sacrificial electron donor that significantly suppress the charge carrier-recombination process, and enhance the hydrogen gas production by avoiding a subsequent gaseous product $\mathrm{H}_{2}$ and $\mathrm{O}_{2}$ ) separation stage. Accumulative all process, leads to increase the overall $\mathrm{H}_{2}$ yield. It irreversibly encountered the photo-generated holes to enhance the photocatalytic electron/hole-separation efficiency and give rise to high quantum yields for hydrogen generation [58].

Therefore, photocatalytic water splitting experiments was performed for the hydrogen generation from the molecular nanocomposite $\mathrm{Ag} @ \mathrm{AgCl} / \mathrm{ZnO}$ that well dispersed in $20 \%$ aqueous methanol scavenger at $\mathrm{pH}=7$, under 1.5 AM G light irradiation as demonstrated by Fig. 5a-c. The hydrogen generation from water in presence of nanocomposite $\mathrm{Ag} @ \mathrm{AgCl} / \mathrm{ZnO}$ might follow the below mentioned reaction mechanism, expressed by Eqs. (10) to (18) $[57,58]$ :

\section{Generation of hydrogen}

$$
\begin{aligned}
& \mathrm{Ag} @ \mathrm{AgCl} \stackrel{\text { Visible light }}{\longrightarrow}(\mathrm{CV}) e^{-}+(\mathrm{VB}) h^{+} \\
& \quad\left(\text { photocarriers }\left(e^{-} / h^{+}\right) \text {generation }\right)
\end{aligned}
$$

$\mathrm{Ag} @ \mathrm{AgCl}(\mathrm{CV}) e^{-} \rightarrow \mathrm{ZnO}(\mathrm{CV}) e^{-} \quad$ (transfer of photoelectron)

$$
\begin{aligned}
& \mathrm{ZnO}(\mathrm{CV}) e^{-}+\mathrm{H}_{2} \mathrm{O} \rightarrow \mathrm{H}^{*}+\mathrm{OH}^{-} \\
& \quad\left(\text { generation of free radical } \mathrm{H}^{*}\right)[59] \\
& h^{+}+\mathrm{OH}^{-} \rightarrow \mathrm{OH}^{*} \quad\left(\text { generation of free radical } \mathrm{OH}^{*}\right) \\
& \mathrm{H}^{*}+\mathrm{H}^{*} \rightarrow \mathrm{H}_{2}(0.00 \mathrm{eV}) \quad\left(\text { generation of } \mathrm{H}_{2}\right) \\
& \quad \text { Consumption of } h^{+} \text {using } \mathrm{CH}_{3} \mathrm{OH}
\end{aligned}
$$

$\mathrm{ZnO}$ or $\mathrm{AgCl}(V B) h^{+}+\mathrm{CH}_{3} \mathrm{OH} \rightarrow \mathrm{CH}_{2} \mathrm{OH}^{*}+\mathrm{H}^{+}(-0.1264 \mathrm{eV})[60]$

$\mathrm{CH}_{2} \mathrm{OH}^{*}+\mathrm{OH}^{*} \rightarrow \mathrm{HOCH}_{2} \mathrm{OH}^{*} \rightarrow \mathrm{HCHO}+\mathrm{H}_{2} \mathrm{O}(-3.848 \mathrm{eV})$

$$
\mathrm{CH}_{2} \mathrm{OH}^{*}+\mathrm{O} \rightarrow \mathrm{OCH}_{2} \mathrm{OH}^{*} \rightarrow \mathrm{HCHO}+\mathrm{OH}^{*}(-3.18 \mathrm{eV})
$$

$$
\mathrm{CH}_{2} \mathrm{OH}^{*}+\mathrm{O} \rightarrow \mathrm{OCH}_{2} \mathrm{OH}^{*} \rightarrow \mathrm{HCOOH}+\mathrm{H}^{*}(-4.125 \mathrm{eV})
$$

The first two reactions (Eqs. 10 and 11) devoted to increase the concentration of photoelectrons on surface of molecular device, for favoring the reduction of water in presence of the sunlight and catalyst. The reactions (Eqs. 12, 14, 16-18), involve in generation of free radicals $\mathrm{H}^{*} /{ }^{*} \mathrm{OH}$ and the formation of the $\mathrm{H}_{2}$ gas/ 
$\mathrm{HCHO}$, respectively. These conversion reactions had a large negative Gibbs energy, thus it intrinsically provides a barrier for the undesired reverse consumption of the $\mathrm{H}_{2}$. Furthermore, two possible mechanisms are proposed for photocatalytic oxidation of methanol: (1) the direct oxidation by photogenerated holes and (2) the indirect oxidation via interfacial ${ }^{*} \mathrm{OH}$ radicals [59]. To distinguish the two mechanisms in practice is still a challenge due to the lack of suitable probe techniques. In present case, it follows the indirect oxidation via interfacial ${ }^{*} \mathrm{OH}$ radicals mechanism that studied by spectroflurimetry. Therefore, the experiments hydroxyl ions converted into hydroxyl radicals under the light exposure, which degrade the methanol and result in production of $\mathrm{HCHO}$ or $\mathrm{HCOOH}$, as shown by Eqs. (15)-(18). Finally, the hydrogen produce through photocatalytic hassle-free reduction of the water. It was found that no detectable amount of hydrogen production was observed even after the $72 \mathrm{~h}$ exposure of water with or without catalyst in dark. The $\mathrm{H}_{2}$ generation capacity of catalyst was continuously estimated for $20 \%$ methanol solution in an argon atmosphere via gas chromatograph [Agilent, TCD (8A column); model: 2780]. Close examination of the spectra told us microwave synthesized samples are more active than conventionally prepared sample.

Gradual increase in hydrogen evolution with time was observed as: from 536.71 to $6082.9 \mu \mathrm{mol} \mathrm{H}_{2} \mathrm{~h}^{-1} \mathrm{~g}^{-1}$ (conventional) and from 556.8 to $6782.32 \mu \mathrm{mol} \mathrm{H}_{2} \mathrm{~h}^{-1} \mathrm{~g}^{-1}$ (Microwave) under irradiation of $300 \mathrm{~W}$ Xe light source. These experimentally observed rate of hydrogen evolution are in good agreement with state of art nanocomposite $\mathrm{Ag} / \mathrm{AgBr} / \mathrm{TiO}_{2}$ that releases $1.00 \mu \mathrm{mol} \mathrm{H}_{2} \mathrm{~h}^{-1} \mathrm{~g}^{-1}$ after $2 \mathrm{~h}$, under the irradiation of $100 \mathrm{~W}$ high-pressure $\mathrm{Hg}$ lamp-with IR filter [61]. Catalytic activity of the nanocomposite Ag@AgCl/ZnO was rejuvenated during the photocatalysis process, as it expressed by Eqs. (1) to (7) $[18,19]$. After photocatalytic activity of $\mathrm{H}_{2}$ production-measured, the catalyst (pinkish grey) was thoroughly washed with distilled water and reused after drying at $80^{\circ} \mathrm{C}$ for $12 \mathrm{~h}$. It was found that there is no significant lost in catalytic activity even after three time use as shown in Fig. 5b, c. Above UV-Vis absorption spectra, spectroflurometric and photocatalytic study gives us sufficient evidence to the electron transfer mechanism of the photocatalytic water splitting for the $\mathrm{H}_{2}$ production process, which is well illustrated by the Fig. $5 \mathrm{~d}$. When the light falls upon the surface of the NCAg@AgCl/ZnO then electron of VB jumped over to the $C B$. Additional CB layers (SURS) of $\mathrm{AgCl}$ required less energy for electron transfer from $V B$ to $C B$ than pristine $\mathrm{AgCl}$. Moreover, this electronic transformation was induced by visible light whether the individual transition in $\mathrm{AgCl}$ or $\mathrm{ZnO}$, was exposed to light. Finally, the electrons transferred to $\mathrm{CB}$ of $\mathrm{ZnO}$ though SURS of $\mathrm{Ag} @ \mathrm{AgCl}$. Where, this photoelectron reduces the water to liberate $\mathrm{H}_{2}$ and holes consumed to generate $\mathrm{HCHO}$ or $\mathrm{HCOOH}$ by oxidation of $\mathrm{CH}_{3} \mathrm{OH}$.

\section{Conclusion}

We explored nanocomposite Ag@AgCl/ZnO NC as a smart material (fabricated by two ways i.e. Microwave and conventional) that can be utilized as a photocatalyst for hydrogen generation through water splitting under visible light exposure. The molecular device exhibits good activity towards photocatalytic hydrogen generation among the state of art photocatalyst of the same class. Moreover, it was established for the molecular device that the photoelectrons generated during the light irradiation was used to reduce water for better hydrogen production and photo-holes reacted with $\mathrm{OH}^{-}$to form ${ }^{*} \mathrm{OH}$ radicals, which used as a scavenger to degrade the methanol into $\mathrm{HCHO}$ or $\mathrm{HCOOH}$. Furthermore, the advancement in the molecular device is in progress by replacing halides with other anions and other plasmonic materials in nanocomposite Ag@AgX/ZnO ( $\mathrm{X}=$ halide).

Acknowledgements NC thanks to the Science and Engineering Research Board, Department of Science and Technology, India (SB/ S1/PC-31/2012) and UGC-DAE, CSR-Indore (CSR-IC-MSRSR-25/CRS233/2017-18/1314) for their financial support and Dr. Gururao of IIT, Kanpur (India) for providing SEM supported Elemental mapping facility to us.

\section{Compliance with ethical standards}

Conflict of interest The authors declare that they have no conflict of interest.

\section{References}

1. Li Q, Guo B, Yu J, Ran J, Zhang B, Yan H, Gong JR (2011) Highly efficient visible-light-driven photocatalytic hydrogen production of CdS-cluster-decorated graphene nanosheets. J Am Chem Soc 133:10878-10884

2. Zhang J, Yu J, Jaroniec M, Gong JR (2012) Noble metal-free reduced graphene oxide- $\mathrm{Zn}_{\mathrm{x}} \mathrm{Cd}_{1-\mathrm{x}} \mathrm{S}$ nanocomposite with enhanced solar photocatalytic $\mathrm{H}_{2}$-production performance. Nano Lett 12(9):4584-4589

3. Xie G, Zhang K, Guo B, Liu Q, Fang L, Gong JR (2013) Graphenebased materials for hydrogen generation from light-driven water splitting. Adv Mater 25:3820-3839

4. Xie G, Zhang K, Fang H, Guo B, Wang R, Yan H, Fang L, Gong JR (2013) A photoelectrochemical investigation on the synergetic effect between CdS and reduced graphene oxide for solarenergy conversion. Chem Asian J 8:2395-2400

5. Bartali R, Speranza G, Aguey-Zinsou KF, Testi M, Micheli V, Canteri R, Fedrizzi M, Gottardi G, Coser G, Crema L, Pucker G, Setijadi E, 
Laidani N (2018) Efficient hydrogen generation from water using nanocomposite flakes based on graphene and magnesium. Sustainable Energy Fuels 2:2516-2525

6. Ding X, Li Y, Zhao J, Zhu Y, Li Y, Deng W, Wang C (2015) Enhanced photocatalytic $\mathrm{H}_{2}$ evolution over $\mathrm{CdS} / \mathrm{Au} / \mathrm{g}-\mathrm{C}_{3} \mathrm{~N}_{4}$ composite photocatalyst under visible-light irradiation. APL Materials 3:104410

7. Chandra M, Bhunia K, Pradhan D (2018) Controlled synthesis of $\mathrm{CuS} / \mathrm{TiO}_{2}$ heterostructured nanocomposites for enhanced photocatalytic hydrogen generation through water splitting. Inorg Chem 57(8):4524-4533

8. Wang P, Weide P, Muhler M, Marschall R, Wark M (2015) New insight into calcium tantalate nanocomposite photocatalysts for overall water splitting and reforming of alcohols and biomass derivatives. APL Materials 3:104412

9. Xu Y, Xu H, Li H, Xia J, Liu C, Liu L (2011) Enhanced photocatalytic activity of new photocatalyst $\mathrm{Ag} / \mathrm{AgCl} / \mathrm{ZnO}$. J Alloys Compound 509:3286-3292

10. Wang D, Duan Y, Luo Q, Li X, Bao L (2011) Visible light photocatalytic activities of plasmonic $\mathrm{Ag} / \mathrm{AgBr}$ particles synthesized by a double jet method. Desalination 270:174-180

11. Li W, Hua F, Yue J, Li J (2013) Ag@AgCl plasmon-induced sensitized $\mathrm{ZnO}$ particle for high-efficiency photocatalytic property under visible light. Appl Surf Sci 285:490-497

12. Adhikari R, Gyawali G, Sekino T, Lee SW (2013) Microwave assisted hydrothermal synthesis of $\mathrm{Ag} / \mathrm{AgCl} / \mathrm{WO}_{3}$ photocatalyst and its photocatalytic activity under simulated solar light. J Solid State Chem 197:560-565

13. Guo R, Zhang G, Liu J (2013) Preparation of Ag/AgCl/BiMg $\mathrm{VO}_{6}$ composite and its visible-light photocatalytic activity. Mater Res Bull 48:1857-1863

14. Hamilton JF (1974) Physical-properties of silver-halide microcrystals. Photogr Sci Eng 18:493-500

15. Kakuta N, Goto N, Ohkita H, Mizushima T (1999) Silver bromide as a photocatalyst for hydrogen generation from $\mathrm{CH}_{3} \mathrm{OH} / \mathrm{H}_{2} \mathrm{O}$ solution. J Phys Chem B 103:5917-5919

16. Schürch D, Currao A, Sarkar S, Hodes G, Calzaferri G (2002) The silver chloride photoanode in photoelectrochemical water splitting. J Phys Chem B 106:12764-12775

17. Lou Z, Huang B, Ma X, Zhang X, Qin X, Wang Z, Dai Y, Liu Y (2012) A 3D AgCl hierarchical superstructure synthesized by a wet chemical oxidation method. Chem Eur J 18:16090-16096

18. Pfanner K, Gfeller N, Calzaferri G (1996) Photochemical oxidation of water with thin $\mathrm{AgCl}$ layers. J Photoch Photobio A 95:175-180

19. Glaus S, Calzaferri G (1999) Silver chloride clusters and surface states. J Phys Chem B 103:5622-5630

20. Calzaferri G, Brühwiler D, Glaus S, Schürch D, Currao A, Leiggener C (2001) Quantum-sized silver, silver chloride and silver sulfide clusters. J Imaging Sci Technol 45:331-339

21. Glaus S, Calzaferri G, Hoffmann R (2002) Electronic properties of the silver-silver chloride cluster interface. Chem Eur J 8:1785-1794

22. Sumi S, Watanabe T, Fujishima A, Honda K (1980) Effect of $\mathrm{Cl}^{-}$ and $\mathrm{Br}^{-}$ions and $\mathrm{pH}$ on the flatband potentials of silver halide sheet crystal electrodes. Bull Chem Soc Jpn 53:2742-2747

23. Zhou J, Cheng Y, Yu J (2011) Preparation and characterization of visible-light-driven plasmonic photocatalyst $\mathrm{Ag} / \mathrm{AgCl} / \mathrm{TiO}_{2}$ nanocomposite thin films. J Photoch Photobio A 223:82-87

24. Longhui $\mathrm{N}$, Zhengqing $\mathrm{H}$, Hongtao $X$, Wangxi $Z$, Borui $Y$, Lei $F$, Shuaihua L (2012) Synthesis of Ag@AgBr photocatalyst and its performance for degradation of methylene blue under visiblelight irridiation. Chin J Catal 33:1209-1216

25. Tian Y, Tatsuma T (2005) Mechanisms and applications of plasmon-induced charge separation at $\mathrm{TiO}_{2}$ films loaded with gold nanoparticles. J Am Chem Soc 127:7632-7637
26. Carja G, Birsanu M, Okadac K, Garcia H (2013) Composite plasmonic gold/layered double hydroxides and derived mixed oxides as novel photocatalysts for hydrogen generation under solar irradiation. J Mater Chem A 1:9092-9098

27. Pirhashemi M, Habibi-Yangjeh A (2014) Preparation of $\mathrm{AgCl}-$ ZnO nanocomposites as highly efficient visible-light photocatalysts in water by one-pot refluxing method. J Alloys Compound 601:1-8

28. Awazu K, Fujimaki M, Rockstuhl C, Tominaga J, Murakami H, Ohki Y, Yoshida N, Watanabe T (2008) A plasmonic photocatalyst consisting of silver nanoparticles embedded in titanium dioxide. J Am Chem Soc 130:1676-1680

29. Chen HM, Chen CK, Chen CJ, Cheng LC, Wu PC, Cheng BH, Ho YZ, Tseng ML, Hsu YY, Chan TS, Lee JF, Liu RS, Tsai DP (2012) Plasmon inducing effects for enhanced photoelectrochemical water splitting: X-ray absorption approach to electronic structures. ACS Nano 6(8):7362-7372

30. Zhu MS, Chen PL, Liu MH (2011) Graphene oxide enwrapped Ag/ $\mathrm{AgX}(\mathrm{X}=\mathrm{Br}, \mathrm{Cl})$ nanocomposite as a highly efficient visible-light plasmonic photocatalyst. ACS Nano 5:4529-4536

31. Zhang YH, Tang ZR, Fu XZ, Xu Y (2011) Nanocomposite of Ag$\mathrm{AgBr}-\mathrm{TiO}_{2}$ as a photoactive and durable catalyst for degradation of volatile organic compounds in the gas phase. J Appl Catal B 106(3-4):445-452

32. Wang XF, Li SF, Ma YQ, Yu HG, Yu JG (2011) $\mathrm{H}_{2} \mathrm{WO}_{4} \cdot \mathrm{H}_{2} \mathrm{O} / \mathrm{Ag} / \mathrm{AgCl}$ composite nanoplates: a plasmonic Z-scheme visible-light photocatalyst. J Phys Chem C 115:14648-14655

33. Cao J, Luo BD, Lin HL, Chen SF (2011) Photocatalytic activity of novel $\mathrm{AgBr} / \mathrm{WO}_{3}$ composite photocatalyst under visible light irradiation for methyl orange degradation. J Hazard Mater 190:700-706

34. Chen HM, Chen CK, Tseng ML, Wu PC, Chang CM, Cheng LC, Huang HW, Chan TS, Huang DW, Liu RS, Tsai DP (2013) Plasmonic $\mathrm{ZnO} / \mathrm{Ag}$ embedded structures as collecting layers for photogenerating electrons in solar hydrogen generation photoelectrodes. Small 9(17):2926-2936

35. Shi H, Chen J, Li G, Nie X, Zhao H, Wong PK, An T (2013) Synthesis and characterization of novel plasmonic Ag/AgX-CNTs $(\mathrm{X}=\mathrm{Cl}, \mathrm{Br}$, I) nanocomposite photocatalysts and dynergetic degradation of organic pollutant under visible light. ACS Appl Mater Interfaces 5(15):6959-6967

36. Christopher P, Xin H, Linic S (2011) Visible-light-enhanced catalytic oxidation reactions on plasmonic silver nanostructures. Nat Chem 3:467

37. Im SH, Lee YT, Wiley B, Xia Y (2005) Large-scale synthesis of silver nanocubes: the role of $\mathrm{HCl}$ in promoting cube perfection and monodispersity. Angew Chem Int Ed 44:2154

38. Carja G, Nakajima A, Dranca S, Dranca C, Okada K (2010) Nanoparticles of nickel oxide: growth and organization on zinc substituted anionic clay matrix by one-pot route at room temperature. J Phys Chem C 114:14722-14728

39. Lou ZZ, Huang BB, Qin XY, Zhang XY, Wang ZY, Zheng ZK, Cheng HF, Wang P, Dai Y (2011) One-step synthesis of AgBr microcrystals with different morphologies by ILs-assisted hydrothermal method. Cryst Eng Comm 6:1789-1793

40. Perreux L, Loupy A (2001) A tentative rationalization of microwave effects in organic synthesis according to the reaction medium, and mechanistic considerations. Tetrahedron 7:9199-9223

41. Singh AK, Nakate UT (2013) Microwave synthesis, characterization and photocatalytic properties of $\mathrm{SnO}_{2}$ nanoparticles. Advances in Nanoparticles 2:66-70

42. Barreto GP, Morales G, Quintanilla ML (2013) Microwave assisted synthesis of $\mathrm{ZnO}$ nanoparticles: effect of precursor reagents, temperature, irradiation time, and additives on nano- $\mathrm{ZnO}$ morphology development. Journal of Materials 2013, 478681 
43. Yamamoto T, Wada Y, Sakata T, Mori H, Goto M, Hibino S, Yanagida S (2004) Microwave-assisted preparation of silver nanoparticles. Chem Lett 33:158

44. Komarneni S, Li DS, Newalkar B, Katsuki H, Bhalla AS (2002) Microwave-polyol process for Pt and Ag nanoparticles. Langmuir 18:5959-5962

45. Tadjarodi A, Khaledi D (2010) Preparation of CuS nanoparticles by microwave irradiation. In: 14th International electronic conference on synthetic organic chemistry, 1-30 Nov 2010 (C010)

46. Ai L, Zhang C, Jiang J (2013) Hierarchical porous AgCl@Ag hollow architectures: self-templating synthesis and highly enhanced visible light photocatalytic activity. Appl Catal B 142-143:744-751

47. Fang Y, Li Z, Xu S, Han D, Lu D (2013) Optical properties and photocatalytic activities of spherical $\mathrm{ZnO}$ and flower-like $\mathrm{ZnO}$ structures synthesized by facile hydrothermal method. J. Alloys Comp. 575:359-363

48. Venkata Subbaiah YP, Prathap P, Ramakrishna Reddy KT (2006) Structural, electrical and optical properties of ZnS films deposited by close-spaced evaporation. Appl Surf Sci 253:2409-2415

49. Callister WD (2004) Materials science and engineering-an introduction, 6th edn. Wiley, New York

50. Suhai S (1986) On the excitonic nature of the first UV absorption peak in polyene. Int J Quantum Chem 29(3):469-476

51. Yu J, Dai G, Huang B (2009) Fabrication and characterization of visible-light-driven plasmonic photocatalyst $\mathrm{Ag} / \mathrm{AgCl} / \mathrm{TiO}_{2}$ nanotube arrays. J Phys Chem C 113(37):16394-16401

52. Draper RB, Fox MA (1990) Titanium dioxide photosensitized reactions studied by diffuse reflectance flash photolysis in aqueous suspensions of $\mathrm{TiO}_{2}$ powder. Langmuir 6(8):1396-1402

53. Hichou AE, Addou M, Ebothé J, Troyon M (2005) Influence of deposition temperature $\left(T_{s}\right)$, air flow rate $(f)$ and precursors on cathodoluminescence properties of $\mathrm{ZnO}$ thin films prepared by spray pyrolysis. J Lumin 113:183-190

54. Li D, Leung YH, Djurišić AB, Liu ZT, Xie MH, Shi SL, Xu SJ, Chan WK (2004) Different origins of visible luminescence in $\mathrm{ZnO}$ nanostructures fabricated by the chemical and evaporation methods. Appl Phys Lett 85:1601

55. Xiang QJ, Yu JG, Cheng B, Ong HC (2010) Microwave-hydrothermal preparation and visible-light photoactivity of plasmonic photocatalyst $\mathrm{Ag}-\mathrm{TiO}_{2}$ nanocomposite hollow spheres. Chem Asian J 5(6):1466-1474

56. Xiang Q, Yu J, Wong PK (2011) Quantitative characterization of hydroxyl radicals produced by various photocatalysts. J Colloid Interface Sci 357:163-167

57. Spellane PJ, Gouterman M, Antipas A, Kim S, Liu YC (1980) Porphyrins. 40. Electronic spectra and four-orbital energies of free-base, zinc, copper, and palladium tetrakis (perfluorophenyl) porphyrins. Inorg Chem 19(2):386-391

58. Schneider J, Bahnemann DW (2013) Undesired role of sacrificial reagents in photocatalysis. J Phys Chem Lett 4:3479-3483

59. Schwarz HA (1992) Reaction of the hydrated electron with water. J Phys Chem 96(22):8937-8941

60. Seetula JA, Kalinovski IJ, Slagle IR, Gutman D (1994) Kinetics of the reaction of $\mathrm{CH}_{2} \mathrm{OH}$ radical with oxygen atoms. Chem Phys Lett 224(5-6):533-538

61. Yu G, Dai GP, Huang BB (2009) Fabrication and characterization of visible-light-driven plasmonic photocatalyst $\mathrm{Ag} / \mathrm{AgCl} / \mathrm{TiO}_{2}$ nanotube arrays. J Phys Chem C 113:16394-16401

Publisher's Note Springer Nature remains neutral with regard to jurisdictional claims in published maps and institutional affiliations. 